\title{
The increasing burden of asthma in South African children: A call to action
}

\author{
R Masekela, ${ }^{1} \mathrm{PhD}$; C L Gray, ${ }^{2} \mathrm{PhD}$; R J Green, ${ }^{3} \mathrm{PhD}$, DSc; A I Manjra, ${ }^{4}$ FCPaed (SA), M Clin Pharm; F E Kritzinger, ${ }^{5}$ Cert Pulmonology (SA) Paed; \\ M Levin, ${ }^{2} \mathrm{PhD} ; \mathrm{H}$ Zar, ${ }^{2} \mathrm{PhD}$; on behalf of the South African Childhood Asthma Working Group \\ ${ }^{1}$ Inkosi Albert Luthuli Central Hospital and Department of Paediatrics and Child Health, School of Clinical Medicine, College of Health Sciences, \\ University of KwaZulu-Natal, Durban, South Africa \\ ${ }^{2}$ Department of Paediatrics and Child Health, Red Cross War Memorial Children's Hospital, and Medical Research Council Unit on Child and \\ Adolescent Health, Faculty of Health Sciences, University of Cape Town, South Africa \\ ${ }^{3}$ Steve Biko Academic Hospital and Department of Paediatrics and Child Health, School of Medicine, Faculty of Health Sciences, \\ University of Pretoria, South Africa \\ ${ }^{4}$ Private Practice, Life Westville Hospital, Durban, South Africa \\ ${ }^{5}$ Netcare Christiaan Barnard Memorial Hospital, Cape Town; and Department of Paediatrics and Child Health, Faculty of Medicine and \\ Health Sciences, Stellenbosch University, Cape Town, South Africa
}

Corresponding author: R Masekela (masekelar@ukzn.ac.za)

\begin{abstract}
Background. Asthma is a heterogeneous condition characterised by chronic inflammation and variable expiratory airflow limitation, as well as airway reversibility. The burden of asthma in children is increasing in low- and middle-income countries and remains underrecognised and poorly managed.

Objectives. To quantify the burden of asthma in the South African (SA) population and identify the risk factors associated with disease severity in the local context.

Methods. The SA Childhood Asthma Working Group (SACAWG) convened in January 2017 with task groups, each headed by a section leader, constituting the editorial committee on assessment of asthma epidemiology, diagnosis, control, treatments, novel treatments and self-management plans. The epidemiology task group reviewed the available scientific literature and assigned evidence according to the Grades of Recommendation Assessment, Development and Evaluation (GRADE) system.

Conclusions. Asthma in children remains a common condition, which has shown an increasing prevalence in urban and rural populations of SA. Of concern is that almost half of children in urban communities experience severe asthma symptoms, and many asthmatics lack a formal diagnosis and thus access to treatment. Exposure to tobacco smoke and living in highly polluted areas increase the severity of wheezing in young children.
\end{abstract}

S Afr Med J 2018;108(7):537-539. DOI:10.7196/SAMJ.2018.v108i7.13162

Asthma is a heterogeneous condition characterised by chronic inflammation and variable expiratory airflow limitation, ${ }^{[1]}$ as well as airway reversibility. Worldwide, asthma is the most common chronic non-communicable disease in children. The most recent global estimate of asthma in adults and children (2008 - 2010) suggests that as many as 334 million people have asthma. ${ }^{[2]}$ The historical view of asthma being a disease of high-income countries no longer holds. Most people affected reside in low- and middle-income countries, where asthma prevalence is estimated to be increasing fastest, while plateauing in high-income countries. Asthma carries a high economic cost to society and the healthcare system, with costs being both direct (hospitalisation, medications and outpatient visits) and indirect (related to absenteeism and loss of productivity). Improving access to care and medications, coupled with use of and adherence to evidence-based treatments, can reduce the economic burden of asthma.

Accurate diagnosis of childhood asthma may be especially challenging in African settings, where respiratory infectious diseases predominate. In non-English-speaking populations, asthma terminology may not be easily translated into local languages. In resource-constrained areas, poor access to healthcare and lack of availability of lung function testing to confirm the diagnosis also contribute to delayed diagnosis. ${ }^{[3]}$ Questionnaire-based studies must be interpreted with caution, as these often rely on literate populations who understand the meaning of words such as 'wheezing' and 'asthma'; this group of individuals may be prone to recall bias. ${ }^{[3]}$ Despite these limitations, the International Study of Asthma and Allergies in Childhood (ISAAC) has provided the most reliable global, comparative data on the prevalence of asthma and other allergic conditions in children, using standard written and video questionnaires, enabling comparison of asthma prevalence between different parts of the world.

\section{Objectives}

We reviewed the current literature on the burden of asthma in South Africa (SA) in the context of other low- and middle-income countries and on rural and urban differences in prevalence and severity of asthma.

\section{Methods}

The SA Childhood Asthma Working Group (SACAWG) convened in January 2017 with six task groups, each headed by a leader (Appendix A), constituting the editorial committee on assessment of asthma epidemiology, diagnosis, control, treatments, novel treatments and self-management plans. The task groups reviewed the available scientific literature on the burden of asthma from high-quality datasets and any local data on asthma prevalence and severity in 
children, and graded the level of evidence and recommendations based on the current evidence.

\section{Asthma prevalence}

\section{Worldwide asthma prevalence}

ISAAC phase I and phase III studies, using identical questionnaires, were performed $\sim 7$ years apart and enabled the investigation of time trends with regard to the symptoms of asthma. Studies were carried out in two age groups: children aged $6-7$ years and adolescents aged 13 - 14 years. ${ }^{[4-6]}$ The large number of children surveyed (>1 million), centres $(N=233)$ and countries $(N=98)$ that participated in ISAAC phase III, made this the most comprehensive global survey of childhood asthma to date. ${ }^{[7]}$

The current overall worldwide prevalence of asthma (ISAAC phase III), measured by reported symptoms in children aged $6-7$ years and $13-14$ years, was $11.5 \%$ and $14.1 \%$, respectively. ${ }^{[8]}$ There was a significant variation in the prevalence of asthma between countries (Table 1). The prevalence of asthma in 13 - 14-year-old black African children was $15.3 \%$, which was higher than the global average. ${ }^{[6]}$ Moreover, the prevalence of childhood asthma in African countries is increasing, compared with that in many high-income settings, where it has stabilised or is decreasing. ${ }^{[3,4]}$ Only two African centres in addition to SA centres included the younger age group of 6 - 7-yearolds. In these centres in Nigeria and Mozambique, the 12-month prevalence of wheeze was $5.6 \%$ and $13.3 \%$, respectively. ${ }^{[9]}$ Overall, in Africa, the 12-month prevalence of wheeze was $10.0 \%$ in the 6 7-years age group. Globally, the current prevalence of wheeze in this age group is $11.5 \%$ and that of severe wheeze $4.9 \%$.

The high, increasing prevalence of childhood asthma in Africa reported by ISAAC has been supported by studies measuring bronchial hyper-responsiveness (BHR) for diagnosing asthma. Such studies have shown a consistent increase in asthma prevalence in rural and urban settings in African countries. ${ }^{[10-14]}$ Furthermore, black African children with asthma have been reported to have more severe symptoms than those in high-income countries, which may relate to factors such as lack of diagnosis, access to care, affordability of therapy, as well as environmental irritants and genetic susceptibility to more severe disease, or a combination of these. ${ }^{[15]}$

\section{Asthma prevalence in South Africa}

The prevalence of asthma in SA children was measured using the ISAAC methodology in Cape Town in 1995 (phase I) and repeated 7 years later in 2002 (phase III). Children aged 13 - 14 years, from all population groups, were included in the study. ${ }^{[8]}$ In 1995 , a total of 5178 children completed the questionnaire and in 2002, 5037 children responded.

The prevalence of lifetime and 12-month wheezing increased between phase I and phase III from $27.7 \%$ to $33.1 \%$ and $16.0 \%$ to $20.3 \%$, respectively (Table 2 ) ${ }^{[8]}$ Similarly, the 12 -month prevalence of night waking with wheeze, severe wheeze, exercise-induced wheeze and nocturnal cough all increased significantly from 1995 to 2002 . Worryingly, approximately half of all children with asthma had severe, uncontrolled symptoms. ${ }^{[7,8]}$ ISAAC phase III was conducted in a rural population in Polokwane, Limpopo, in 4660 children aged 13 - 14 years. The 12-month prevalence of asthma was $18 \%$, while the prevalence of severe asthma symptoms in Cape Town was less $(6.6 \%) .{ }^{[6]}$ Using the ISAAC phase III methodology in a younger cohort $(N=2437)$ of 6 - 7-year-old black African children in Polokwane, the 12-month prevalence of wheeze and severe wheeze was $11.2 \%$ and $5.7 \%$, respectively. ${ }^{[9]}$ In this cohort, various potential risk factors and asthma symptoms were investigated. Living in a rural area was protective, which significantly decreased the likelihood of wheeze by $31 \%$. Risk factors for the increased likelihood of wheeze included: exposure to environmental tobacco smoke (77\%), eczema (104\%) and rhinoconjunctivitis (226\%) symptoms. The presence of rhinoconjunctivitis increased the likelihood of severe wheeze by $107 \%$. $^{\left[{ }^{9]}\right.}$

Studies in SA children measuring BHR confirmed the increase in asthma prevalence. In 1979, the first study of asthma prevalence in SA

Table 1. Current prevalence of asthma symptoms by world region in 6 - 7-year and 13 - 14-year age groups as measured in ISAAC phase III*

\begin{tabular}{|c|c|c|c|c|c|c|}
\hline \multirow[b]{2}{*}{ Region } & \multicolumn{3}{|c|}{$6-7$ years } & \multicolumn{3}{|c|}{13 - 14 years } \\
\hline & $N$ & $n$ & $\%$ & $N$ & $n$ & $\%$ \\
\hline Africa & 5865 & 589 & 10.0 & 66308 & 10168 & 15.3 \\
\hline Asia-Pacific & 59979 & 5719 & 9.5 & 99634 & 8731 & 8.7 \\
\hline Eastern Mediterranean & 40573 & 3824 & 9.4 & 51705 & 4801 & 9.2 \\
\hline Indian subcontinent & 50092 & 3392 & 6.7 & 55783 & 3884 & 6.9 \\
\hline Latin America & 93774 & 16256 & 17.3 & 165900 & 26350 & 15.9 \\
\hline North America & 4012 & 767 & 19.1 & 141009 & 30427 & 21.6 \\
\hline Northern and Eastern Europe & 42548 & 3715 & 8.7 & 72057 & 7009 & 9.7 \\
\hline Oceania & 13888 & 3020 & 21.7 & 36299 & 6301 & 17.4 \\
\hline Western Europe & 77722 & 7487 & 9.6 & 107673 & 15483 & 14.4 \\
\hline Global total & 388811 & 44799 & 11.5 & 798685 & 112630 & 14.1 \\
\hline
\end{tabular}

Table 2. Current prevalence of asthma symptoms (12-month prevalence rate of wheeze) by region in South Africa in 6 - 7-year and 13 - 14-year age groups as measured in ISAAC phase I and phase III

\begin{tabular}{|c|c|c|c|c|}
\hline \multirow[b]{2}{*}{ Region } & \multicolumn{2}{|c|}{$6-7$ years } & \multicolumn{2}{|c|}{$13-14$ years } \\
\hline & $N$ & $\%$ & $N$ & $\%$ \\
\hline Cape Town (ISAAC I) & - & - & 5178 & 16.0 \\
\hline Cape Town (ISAAC III) & - & - & 5037 & 20.3 \\
\hline Polokwane (ISAAC III) & 2437 & 11.2 & 4660 & 18.0 \\
\hline
\end{tabular}


children found a 30 -fold higher prevalence in urban (3.1\%) compared with rural $(0.01 \%)$ Xhosa children aged 7 - 9 years. ${ }^{[10]} \mathrm{A}$ follow-up study in 2003 reported an increase in asthma prevalence in urban and rural children, with a reduction in the urban-rural gradient. ${ }^{[13]}$ Increased BHR was associated with rural children adopting an urban lifestyle. A later study measuring BHR also confirmed an increase in asthma prevalence in urban (15\%) and rural (9\%) Xhosa children, with a reduction in the urban-rural gradient. ${ }^{[14]}$ Obesity was identified as a risk factor for an increase in BHR. The most recent study showed BHR in $16 \%$ of peri-urban black African teenagers, with high rates of allergen sensitisation in individuals with BHR. ${ }^{[15]}$

\section{Risk factors for asthma}

Eczema is an important risk factor for asthma, and longitudinal studies have shown that from one-third to one-half of children with eczema develop asthma. ${ }^{[17]}$ In a SA study of 100 children with atopic dermatitis, $39 \%$ described symptoms of asthma according to the ISAAC questionnaire, and in $29 \%$ asthma was diagnosed by a doctor ${ }^{[18]}$ Asthma prevalence increased with age: at the time of the study asthma symptoms were present in $22 \%$ of children $<2$ years old, $43 \%$ of 2 - 4 -year-olds and $50 \%$ of children $>4$ years old. ${ }^{[18]}$

Industrial pollution is a further risk factor associated with a higher prevalence of asthma. A study in Durban questioned 422 learners (average age 10.5 years) on symptoms of asthma. In this cohort, the presence of symptoms that were consistent with asthma of any severity was $32 \%$, and the prevalence of doctor-diagnosed asthma was 13.0 - $16.5 \%$, depending on the area surveyed. Children from areas with higher levels of industrial pollution had a higher prevalence of respiratory health problems. ${ }^{[19]}$ In a separate study in a highly polluted area in the south of Durban, which included 248 school-aged participants from grades 3 to $7,52 \%$ had asthma of any severity, $11 \%$ had moderate-to-severe persistent asthma, and $21 \%$ had marked airways hyperreactivity on methacholine challenge testing. ${ }^{[20]}$

\section{Asthma morbidity and mortality}

Almost half of children in Cape Town who reported asthma in ISAAC phase III had severe symptoms. ${ }^{[8]}$ Furthermore, $>30 \%$ of children with severe asthma symptoms had never been formally diagnosed with asthma. ${ }^{[7,14]}$ In addition to morbidity from childhood asthma, SA has a very high rate of asthma-related deaths, suggesting that lack of appropriate diagnosis, treatment or access to care may be important considerations. ${ }^{[16-18]}$ Although SA was ranked 25th worldwide for the prevalence of asthma, it ranked 4th in asthma mortality in the 5 34-year-old age group and 5th for asthma case fatality rates, with an estimated 18.5 per 100000 asthmatics. ${ }^{[17,18]}$

\section{Conclusion}

Childhood asthma remains a common condition, which has shown an increasing prevalence in urban and rural populations in SA. Of concern is that almost half of children in urban communities experience severe asthma symptoms, and many asthmatics lack a formal diagnosis and thus access to treatment. Exposure to tobacco smoke and living in highly polluted areas increase the severity of wheezing in young children.

Acknowledgements. We acknowledge the hard work and contribution of the South African Childhood Asthma Working Group (SACAWG) members. We also acknowledge the huge contribution of the late Prof. Cas Motala, who was convener of the past three SACAWG guidelines.

Author contributions. RM: review, write-up and manuscript editing; HZ, CLG: conceptualisation, methodology, write-up and manuscript editing; and ML, RJG, AIM, FEK: write-up and manuscript editing.
Funding. SACAWG conducted a workshop that received an unconditional educational grant from the Allergy Society of South Africa - funded by Novartis. Conflicts of interest. None.

1. Global Initiative for Asthma. www.ginasthma.org (accessed 22 January 2017).

2. The Global Asthma Report. www.globalasthmareport.org (accessed 22 January 2017),

3. Zar HJ, Levin ME. Challenges in treating paediatric asthma in developing countries. Pediatr Drugs 2012;14(6):1-7.

4. Asher MI, Montefort S, Bjorksten B, et al., and the ISAAC Phase Three Study Group. Worldwide trends in the prevalence of symptoms of asthma, allergic rhinoconjunctivitis and eczema in childhood: ISAAC Phases One and Three repeat multicountry cross-sectional surveys. Lancet 2006;368(9537):733-737. Phases One and Three repeat multicountry cross
https://doi.org/10.1016/S0140-6736(6)69283-0

5. Pearce N, Ait-Khaled N, Beasley R, et al., and the ISAAC Phase Three Study Group. Worldwide trends in the prevalence of asthma symptoms: Phase III of the International Study of Asthma and Allergies in in the prevalence of asthma symptoms: Phase III of the International Study of Asthma and All
Childhood (ISAAC). Thorax 2007;62(9):757-765. https://doi.org/10.1136/thx.2006.070169

6. Ait-Khaled N, Odhiambo J, Pearce N, et al. Prevalence of symptoms of asthma, rhinitis and eczema in 13- to 14-year-old children in Africa: The International Study of Asthma and Allergies in Childhood
1it-Khaled 13- to 14-year-old children in Africa: The International Study of Asthma and Allergies in
Phase III. Allergy 2007;62(3):247-258. https://doi.org/10.1111/j.1398-9995.2007.01325.x

7. Mallol J, Crane J, von Mutius E, Odhiambo J, Keil U, Stewart A, the ISAAC Phase Three Study Group. The International Study of Asthma and Allergies in Childhood (ISAAC) phase three: A global synthesis. Allergol Immunopathol (Madr) 2013;41(2):73-85. https://doi.org/10.1016/j.aller.2012.03.001

8. Zar HJ, Ehrlich RI, Workman L, Weinberg EG. The changing prevalence of asthma from 1995 to 2002

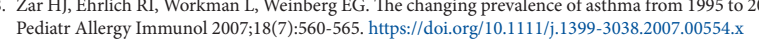

Wedichmann J, Wolvaardt J, Maritz C, Voyi K. Household conditions, eczema symptoms and rhinitis symptoms: Relationship with wheeze and severe wheeze in children living in the Polokwane area symptoms: Relationship with wheeze and severe wheeze in children living in the Polokwane area,
South Africa. Matern Child Health J 2009;13(1):107-118. https://doi.org/10.1007/s10995-007-0309-x

10. Van Niekerk CH, Weinberg EG, Shore SC, et al. Prevalence of asthma: A comparative study of urban and rural Xhosa Children. Clin Allergy 1979; $9(4): 319-324$. https://doi.org/10.1111/j.1365-2222.1979.tb02489.x
rol Keeley D, Neil P, Gallivan S. Comparison of the prevalence of reversible airway obstruct in rural and Keeley D, Neil P, Gallivan S. Comparison of the prevalence of reversible airway obstruct in rur
urban Zimbabwean children. Thorax 1991;46(8):549-553. https://doi.org/10.1136/thx.46.8.549

urban Zimbabwean children. Thorax 1991; 4 a (8):549-553. https://doi.org/10.1136/thx.46.8.549
Addo Yobo E, Custovic A, Taggard SC, et al. Exercise-induced bronchospasm in Ghana: Differences in prevalence between urban and rural school-children. Thorax 1997;52(2):161-165. https://doi.
inter in prevalence between u
org/10.1136/thx.52.2.161

13. Steinman HA, Donson H, Kawalski M, et al. Bronchial hyper-responsiveness and atopy in urban, periurban and rural South African children. Paediatr Allergy Immunol 2003;14(5):383-393. https://doi org/10.1034/j.1399-3038.2003.00062.x

4. Calvert J, Burney P. Effect of body mass on exercise-induced bronchospasm and atopy in Africa children. J Allergy Clin Immunol 2005;116(4):773-779. https://doi.org/10.1016/j.jaci.2005.05.025 15. Levin ME, Muloiwa R, Motala C. Associations between asthma and bronchial hyper-responsiveness with allergy and atopy phenotypes in urban black South African teenagers. S Afr Med J 2011;101(7):472-476. 16. Lai CK, Beasley R, Crane J, Foliaki S, Shah J, Weiland S, the ISAAC Phase Three Study Group. Global variation in the prevalence and severity of asthma symptoms: Phase three of the International Study of Asthma and Allergies in Childhood (ISAAC). Thorax 2009;64(6):476-483. https://doi.org/10.1136/thx.2008.106609

17. Van der Hulst AE, Klip H, Brand PL. Risk of developing asthma in young children with atopic eczema: $A$ systematic review. J Allergy Clin Immunol 2007;120(3):565-569. https://doi.org/10.1016/j.jaci.2007.05.042

8. Gray CL, Levin ME, Zar HJ, et al. Food allergy in South African children with atopic dermatitis. Pediatr Allergy Immunol 2014;25(6):572-579. https://doi.org/10.1111/pai.12270

9. Naidoo RN, Robins TG, Batterman S, Mentz G, Jack C. Ambient pollution and respiratory outcomes among schoolchildren in Durban, South Africa. S Afr J Child Health 2013;7(4):127-134. https://do org/10.7196/SAJCH.598

20. Kistnasamy EJ, Robins TG, Naidoo R, Batterman S, Mentz GB, Jack C. The relationship between asthma and ambient air pollutants among primary school students in Durban, South Africa. Int J Environ Health 2008;2(3-4):365. https://doi.org/10.1504/IJENVH.2008.020929

21. Masoli M, Fabian D, Holt S, Beasley R, Global Initiative for Asthma (GINA) Program. The global burden of asthma: Executive summary of the GINA Dissemination Committee report. Allergy 2004;59(5):469-478. https://doi.org/10.1111/j.1398-9995.2004.00526.x

22. Zar HJ, Stickells D, Toerien A, Wilson D, Klein M, Bateman ED. Changes in fatal and near fatal asthm in an urban area of South Africa from 1980 - 1997. Eur Respir J 2001;18(1):33-37. https://doi.org/10. $1183 / 09031936.01 .00081801$

23. Beran D, Zar HJ, Perrin C, Menezes AM, Burney P, for the Forum of International Respiratory Societies Working Group Collaboration. Burden of asthma and chronic obstructive pulmonary disease and access to essential medicines in low-income and middle-income countries. Lancet Respir Med 2015;3(2):159-170. https://doi.org/10.1016/S2213-2600(15)00004-1

Accepted 7 May 2018.

\section{Appendix A. The SA Childhood}

Asthma Working Group (SACAWG)

Epidemiology: H Zar (leader), Western Cape; C Gray, Western Cape. Diagnosis of asthma: R Masekela (leader), KwaZulu-Natal; S M Risenga, Limpopo; O P Kitchin, Gauteng; P Goussard, Western Cape.

Assessment of asthma control: R J Green (leader), Gauteng; D White, Gauteng; G Davis, Gauteng.

Pharmacotherapy: F E Kritzinger (leader), Western Cape; A Jeevanathrum, Gauteng; P de Waal, Free State; $\mathbf{S}$ Kling, Western Cape; A Vanker, Western Cape; T C Gray, Western Cape; J Morrison, Western Cape; A Puterman, Western Cape; E Zollner, Western Cape; D Rhode, Western Cape.

Pharmacotherapy - other therapies: A I Manjra (leader), KwaZulu-Natal; P M Jeena, KwaZulu-Natal; V Naidoo, KwaZulu-Natal; M Annamalai, KwaZulu-Natal; A van Niekerk, Gauteng.

Self-management plans: M Levin (leader), Western Cape; S Emanuel, Western Cape; D Hawarden, Western Cape; H Katz, Gauteng. 